\title{
O Processo de Construção do Jogo Inteligente Tangível: Hash 3D
}

\author{
Érica J. S. Scheffel ${ }^{1,2}$, Claudia L. R. Motta ${ }^{1,2}$, Carlo E. T. Oliveira ${ }^{1}$, Carla Verônica \\ M. Marques ${ }^{1}$
}

${ }^{1}$ Instituto Tércio Pacitti de Aplicações e Pesquisas Computacionais - Universidade Federal do Rio de Janeiro (UFRJ)

${ }^{2}$ Programa de Pós-Graduação em Informática - Universidade Federal do Rio de Janeiro (UFRJ)

Av. Athos da Silveira Ramos, 274 - 21.941-916 - Rio de Janeiro - RJ - Brasil

\{ericascheffel, claudiam, carlo, carlaveronica\}@nce.ufrj.br

\begin{abstract}
This article describes the process of building the physical part of the Tangible Intelligent Game, called Hash 3D, whose human-machine interaction is performed using Arduino technology. The objective of the game is to provide, in a computerized, playful and totally manipulable way, a study on the cognitive processes that make up intelligence, according to PASS Theory, such as Planning, Attention, Successive and Simultaneous Processing [Luria 1966].
\end{abstract}

Resumo. Este artigo descreve o processo de construção da parte física do Jogo Inteligente Tangível, denominado Hash 3D, cuja interação homem-máquina é realizada por meio da tecnologia Arduino. O objetivo do jogo é oportunizar, de forma computadorizada, lúdica e totalmente manipulável, um estudo sobre os processos cognitivos que compõem a inteligência, segundo a Teoria PASS, tais como Planejamento, Atenção, Processamento Sucessivo e Simultâneo [Luria 1966].

\section{Introdução}

Há décadas que cientistas cognitivos trabalham projetando artefatos capazes de mensurar aspectos da formação cognitiva a partir da captura refinada de comportamentos operativos observáveis, como Jean Piaget, o qual descreveu o processo de formação da inteligência da criança com base nas suas interações provocadas por meio de cordões, pedaços de madeira, bastões e bolinhas de massa [Piaget 1986]; da mesma forma, Barbel Inhelder utilizou jarras de água e uma série de pequenos cubos de madeira para, no fim, indagar sobre futuras construções de "máquinas de arquitetura psicogenética" que obtivessem um conhecimento cada vez mais aprofundado dos processos que sustentam a trajetória das descobertas na criança [Inhelder et al. 1996]; por conseguinte, J. P. Das, Naglieri e Kirby desenvolveram testes, baseados na Teoria PASS de Luria, onde um dos muitos artifícios utilizados foi apresentar nomes de cores impressos em cores diferentes, como a palavra "vermelho" apresentada na cor verde, a fim de verificar se a criança é capaz de dizer o nome da cor impressa, visando observar níveis de atenção, por exemplo [Das et al. 1994]. Sendo assim, dentre as mais recentes contribuições, no que diz respeito aos artefatos construídos para 
mensuração cognitiva aliada à tecnologia, a proposta dos Games Inteligentes foi base para o desenvolvimento deste estudo por se tratar de jogos de computador programados com inteligência artificial que observam e habilitam funções cognitivas de alta complexidade, a partir da observação de suas reações, diante da busca de soluções para os desafios propostos [Marques 2017].

Justificado pela importância dos objetos manipulativos no engajamento sensorial, conforme apresentado por Maria Montessori na criação de seu acervo material sensóriomotor educativo, uma vez que o processo de aprendizagem das crianças envolve vários sentidos utilizados concomitantemente como a visão, o tato e a audição [Montessori 1916 apud Zuckerman et al. 2005], a proposta dos Jogos Inteligentes Tangíveis como instrumento de mensuração cognitiva [Scheffel 2019] acrescenta o fator psicomotricidade às recentes propostas de análises computadorizadas de aspectos intelectivos.

A relevância de pesquisas que objetivam compreender os processos de aquisição de conhecimento se concretiza no déficit de aprendizagem dos brasileiros, demonstrado nos resultados de avaliações em escala mundial, como o teste PISA (Programa Internacional de Avaliação de Alunos). Segundo um estudo da $\mathrm{OCDE}^{l}$ (Organização para a Cooperação e Desenvolvimento Econômico) publicado em 2018 e divulgado na $\mathrm{BBC}^{2}$, apenas $2,1 \%$ dos alunos carentes no Brasil conseguem atingir o nível de bons conhecimentos em ciências, matemática e leitura. Além disso, estudos de Franco Seminério mostraram que as crianças que se desenvolvem em um meio social com menos recursos, sem acesso às experiências necessárias para sua formação cognitiva, se tornam adultos com menor capacidade intelectual e esse não é um problema educacional, mas social [Seminério 1984]. Por esse motivo, a educação pode ter, como aliada, a disponibilidade de novos instrumentos capazes de detectar possíveis falhas existentes nos processos da formação cognitiva, com o propósito de que sejam reparadas a partir de estímulos ofertados de forma lúdica e espontânea. Sendo assim, a principal contribuição do presente trabalho é o processo de construção da parte física do Jogo Inteligente Tangível Hash 3D, no qual a tecnologia Arduino foi utilizada para captação das ações que promoverão a mensuração cognitiva, em conformidade com as teorias que o definem, para que, posteriormente, seja concluída a programação em Python que efetuará os resultados, a qual se encontra em fase de desenvolvimento.

\section{Características do Hash 3D}

Trata-se de uma versão mais elaborada, acrescida de tridimensionalidade e novas possibilidades de vitória, de um dos jogos mais antigos e praticados por pessoas de todas as idades e de todos os lugares do mundo: o Jogo da Velha. O Hash 3D tem como objetivo a formação sequencial, em linha reta e em qualquer direção possível (horizontal, vertical ou diagonal), de três elementos da mesma cor ou mesmo símbolo. Para isso, cada jogador dispõe de quinze peças distribuídas em três cores, portando cinco tipos de símbolos diferentes, cada símbolo em uma das três cores disponíveis, conforme demostrado na Figura 1. Sendo assim, cada jogador possui cinco peças para formar sequências de mesma cor e apenas três peças para formar sequências de mesmo símbolo. Cada jogador só pode formar sequências com suas próprias peças, diferenciadas pela cor dos símbolos, os quais podem ser pretos ou brancos, assim como no Jogo de Xadrez. Os jogadores se revezam e quando alguma

\footnotetext{
1 https://www.oecd.org/pisa/

2 https://www.bbc.com/portuguese/brasil-45961795
} 
sequência é completada corretamente, um sinal sonoro é disparado como única forma de feedback oferecida em resposta às ações realizadas. Cada dupla de jogadores deve participar de cinco partidas e as regras do jogo não são repassadas aos mesmos, para que a primeira partida seja uma evidência do processo de Assimilação e a quinta (última partida), do processo de Acomodação, conforme a Teoria da Equilibração das Estruturas Cognitivas [Piaget 1976].

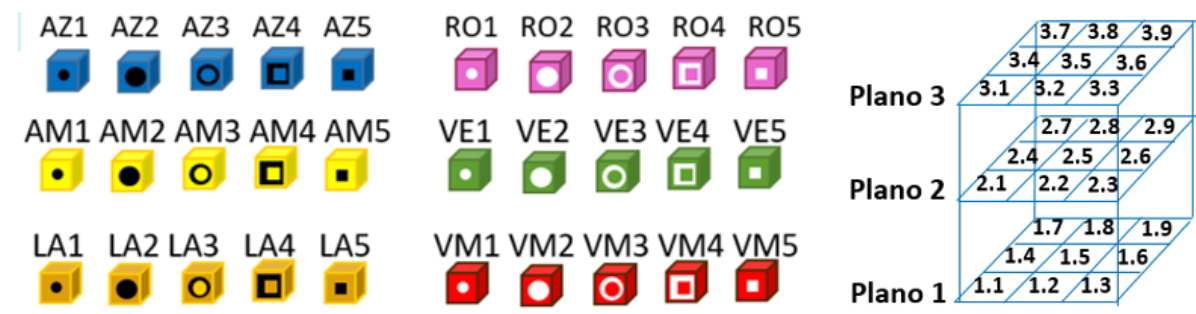

Figura 1. Identificação das peças e casas do tabuleiro 3D

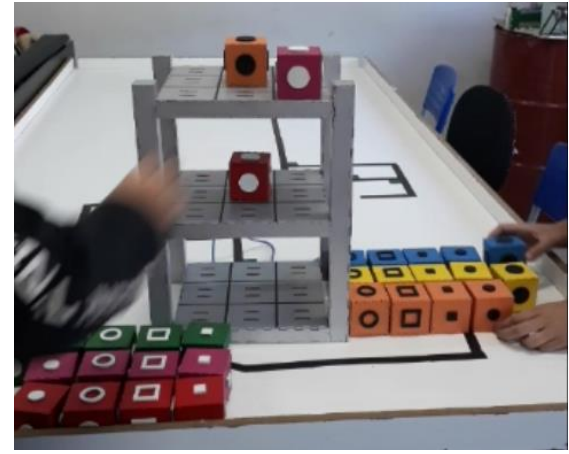

Figura 2. Alunos do Ensino Fundamental jogando o Hash 3D

\section{O que é mensurado no Hash 3D?}

Segundo a Teoria PASS [Luria 1966] a inteligência humana é composta de quatro processos cognitivos: o Planejamento é responsável pelo controle e organização do comportamento para que as melhores estratégias aplicáveis na resolução de um problema sejam selecionadas, assim como o monitoramento de seu desempenho; a Atenção refere-se ao processo responsável pela manutenção do foco, a fim de que as demais distrações sejam ignoradas e o mesmo seja mantido nos estímulos de maior importância durante a resolução de um problema; o Processamento Sucessivo é responsável pela decodificação, transformação e retenção de informações para organização de itens separados em uma série, ou seja, são estímulos organizados em uma ordem sequencial; o Processamento Simultâneo também é responsável pela decodificação, transformação e retenção de informações, porém envolve a capacidade necessária para que os estímulos separados sejam integrados em um todo coeso e inter-relacionado.

Diante disso, ações que possam ocorrer durante as partidas do jogo foram predefinidas como ações correspondentes aos processos descritos na Teoria PASS por seguirem o mesmo caminho de desenvolvimento racional. No Modelo Dimensional, apresentado no Quadro 1, estão determinadas as ações e as unidades a serem medidas; nos diagramas extraídos da base teórica (Figuras 3 e 5), que trata da avaliação de processos cognitivos [Das et al. 1994], encontram-se os caminhos de cada um dos processos. Estas 
ações são demarcadas em um sistema de atribuição de um ponto para cada uma delas, em consonância com seu referido processo.

\section{Quadro 1. Modelo Dimensional e Crivo Computacional}

\begin{tabular}{|c|c|}
\hline Modelo de Planejamento: & Análise $\rightarrow$ Desenvolvimento $\rightarrow$ Avaliação $\rightarrow$ Modificação \\
\hline $\begin{array}{l}\text { Ações de Planejamento no } \\
\text { Hash 3D: }\end{array}$ & $\begin{array}{l}\text { - Início de uma formação sequencial com duas peças de mesma cor ou símbolo; } \\
\text { - Início estratégico na casa } 2.5 \text { aumentando as possibilidades de vitória; } \\
\text { - Reversão do jogo: defensiva seguida de ataque; } \\
\text { - Vitória de dupla possibilidade (duas direções distintas). }\end{array}$ \\
\hline Modelo de Atenção: & Controle dos Níveis de Alerta $\longrightarrow$ Seleção dos Estímulos Mais Importantes \\
\hline $\begin{array}{l}\text { Ações de Atenção no Hash } \\
\text { 3D: }\end{array}$ & $\begin{array}{l}\text { - Bloqueio à vitória do adversário; } \\
\text { - Percepção da própria vitória. }\end{array}$ \\
\hline $\begin{array}{l}\text { Modelo de Processamento } \\
\text { Sucessivo: }\end{array}$ & Integração de Estímulos em Série $\rightarrow$ Inspeção Linear e Definida \\
\hline $\begin{array}{l}\text { Ações de Processamento } \\
\text { Sucessivo no Hash 3D: }\end{array}$ & $\begin{array}{l}\text { - Início de uma formação sequencial com duas peças de mesma cor ou símbolo; } \\
\text { - Formação sequencial em um único plano; } \\
\text { - Utilização da segunda peça de mesma cor ou símbolo, mesmo sem sequência. }\end{array}$ \\
\hline $\begin{array}{l}\text { Modelo de Processamento } \\
\text { Simultâneo: }\end{array}$ & $\begin{array}{r}\text { Estímulos Percebidos } \\
\text { Estímulos Lembrados } \\
\text { Aspectos Conceituais dos Estímulos }\end{array}$ \\
\hline $\begin{array}{l}\text { Ações de Processamento } \\
\text { Simultâneo no Hash 3D: }\end{array}$ & $\begin{array}{l}\text { - Utilização de mais de um plano na segunda jogada com início de sequência; } \\
\text { - Bloqueio à vitória do adversário envolvendo os três planos; } \\
\text { - Percepção da própria vitória envolvendo os três planos; } \\
\text { - Vitória na diagonal envolvendo os três planos; } \\
\text { - Vitória de dupla possibilidade (duas direções distintas). }\end{array}$ \\
\hline
\end{tabular}

\subsection{O Processo de Planejamento}

De acordo com a Teoria PASS [Luria 1966, 1980], [Das et al. 1994], o Planejamento é considerado como a essência da inteligência humana por envolver a aptidão necessária para fazer novas perguntas, resolver problemas e auto monitorar a codificação de informações. Segundo os autores, após analisar o problema, é durante o processo de Planejamento que o indivíduo chega no estágio de desenvolvimento de métodos para resolvê-lo e alcançar seu objetivo. Sendo assim, ações identificadas como resultantes desse processo, descritas no quadro acima, seguem o caminho apresentado no diagrama esquerdo da Figura 3, por exemplo, estar diante de um jogo inédito e sem instruções (problema apresentado) e se 
questionar: eu preciso de um plano? Eu tenho esse conhecimento? Minha ideia inicial para resolvê-lo foi razoável? Funcionou? Eu tenho um plano melhor? [Das et al. 1994].

\subsection{O Processo de Atenção}

Responsável por regular o tom cortical e a manutenção dos níveis de foco nos estímulos mais relevantes para resolver o problema [Luria 1966, 1973, 1980]. Em uma pesquisa, cujo objetivo é mensurar aspectos da formação cognitiva, é fundamental verificar o controle dos níveis de alerta pois somente quando uma condição de vigília adequada é alcançada que um indivíduo pode receber e processar informações [Das et al. 1994]. Além dos níveis de alerta, em um mundo cada vez mais sobrecarregado de estímulos, a seleção dos estímulos de maior importância para resolver o problema in loco define o sucesso das possíveis estratégias esquematizadas no Planejamento, uma vez que um processo está condicionado ao outro, segundo os autores. A Figura 3 apresenta, à direita, o caminho que o processo de Atenção percorre em sua atuação.

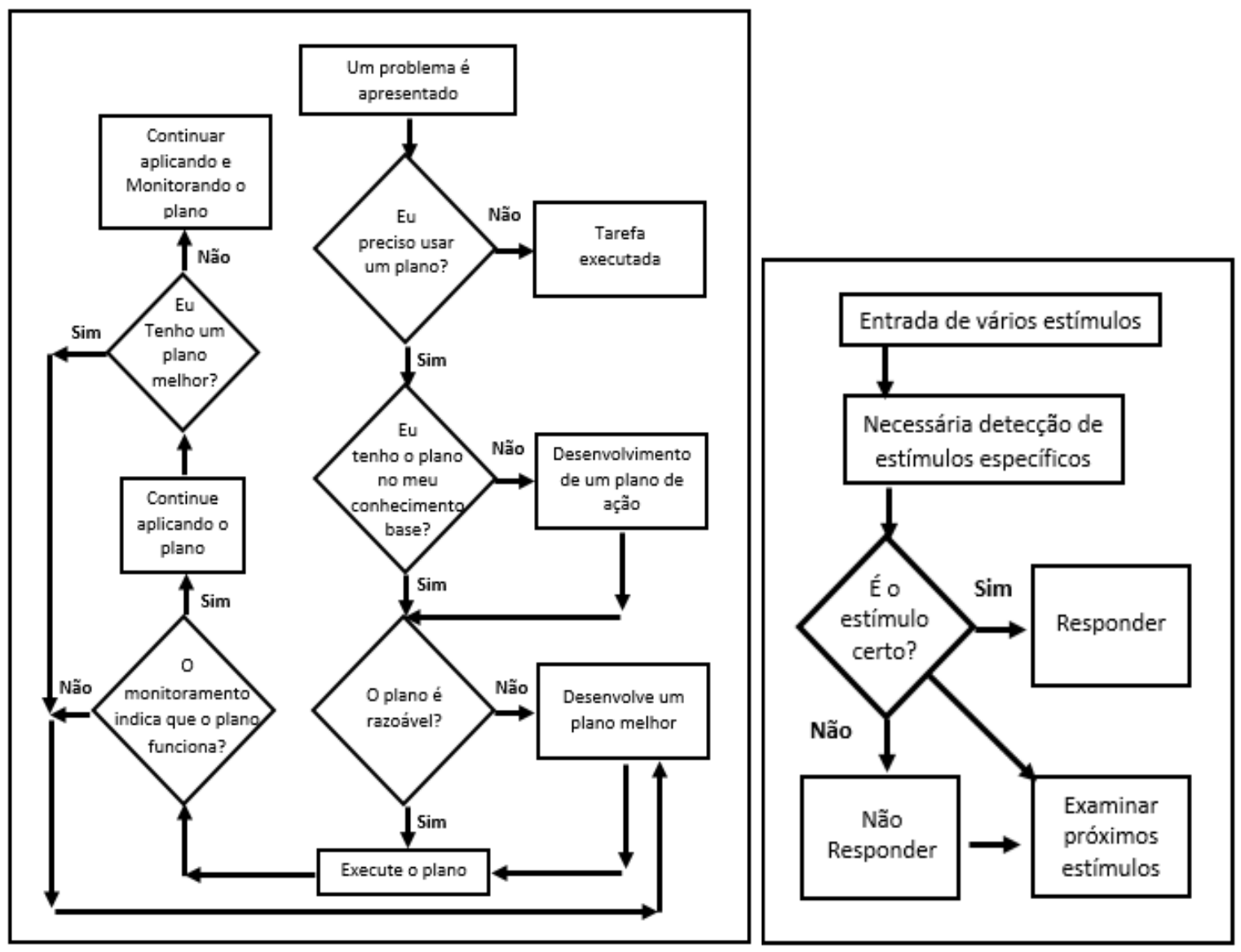

Figura 3. Diagramas dos caminhos dos processos de Planejamento (à esquerda) e Atenção (à direita) [Das et al. 1994]

Portanto, bloquear a vitória alheia ou perceber sua própria vitória, são ações resultantes da seleção do estímulo certo em meio às demais peças alocadas no tabuleiro, principalmente quando já se encontra cheio, assim como os estímulos externos ao jogo: ruídos, objetos visuais, pessoas no ambiente etc. 


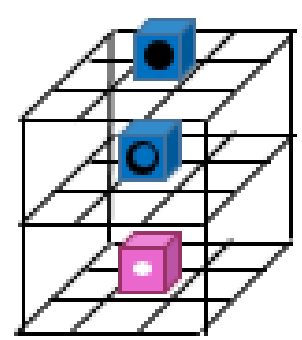

Figura 4. Exemplo de marco de Atenção para o portador da peça rosa

\subsection{O Processamento Sucessivo}

Conforme citado por Das, Naglieri e Kirby (1994), o Processamento Sucessivo envolve a integração de estímulos em série onde os elementos formam uma progressão em cadeia, cuja inspeção ocorre sem topografia, ou seja, sem tridimensionalidade. Portanto, ao contrário do Processamento Simultâneo em que os elementos são inspecionados, codificados e interrelacionados de várias maneiras, o Processamento Sucessivo promove a inspeção linear e definida, conforme ilustrado no diagrama esquerdo da Figura 5. Essa integração de estímulos em série, juntamente com a inspeção linear e definida, são observadas durante as partidas do Hash 3D quando há tentativas de formação sequencial, em linha reta, com peças de mesma cor ou mesmo símbolo, pois presume-se que há uma codificação do indivíduo ao promover esse tipo de organização linear, a fim de atingir algum objetivo.
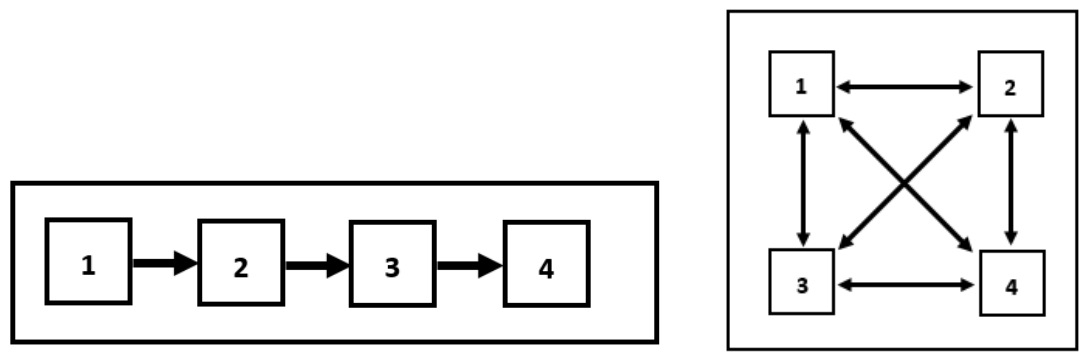

Figura 5. Diagrama dos caminhos do Processamento Sucessivo (à esquerda) e do Processamento Simultâneo (à direita) [Das et al. 1994]

\subsection{O Processamento Simultâneo}

Assim como o Processamento Sucessivo, o Processamento Simultâneo também é responsável por receber, processar e reter informações que uma pessoa obtém do ambiente, uma vez que ambos compõem a segunda unidade funcional ${ }^{3}$ dos processos mentais humanos [Luria 1966]. A diferença é que o Processamento Simultâneo envolve a integração de estímulos em grupos ou o reconhecimento de um número ilimitado de estímulos que compartilham uma característica comum, exigindo que todos estejam relacionados [Das et al. 1994]. Segundos os autores, estímulos percebidos, estímulos lembrados e os aspectos conceituais dos estímulos são inter-relacionados e inspecionados durante o Processamento Simultâneo, como as tarefas verbais que exijam uma execução do tipo: desenhe um círculo sob um quadrado à direita de uma cruz no topo de um triângulo. Para executar essa tarefa, o

\footnotetext{
${ }^{3}$ A primeira unidade funcional refere-se ao processo de Atenção; a segunda unidade funcional refere-se aos Processamentos Sucessivos e Simultâneos (entrada de estímulos externos); a terceira unidade funcional corresponde ao processo de Planejamento [Luria 1966, 1973, 1980].
} 
indivíduo deve examinar a relação entre o círculo, o quadrado e a cruz, em seu arranjo espacial, a partir da estrutura gramatical lógica da afirmação" [Das et al. 1994]. Nesse caso, o requisito é que os componentes da tarefa precisam ser inter-relacionados, como as sequências que abrangem os três planos do tabuleiro, as quais evidenciam a necessidade de inter-relação entre uma série de fatores. Dentre esses fatores, encontram-se possíveis direções para a formação sequencial; se a mesma está sendo realizada com cores ou símbolos ou se o adversário está prestes a concluir alguma sequência que envolva os três planos, conforme ilustrados no diagrama da Figura 8.

\subsection{O Processo de Assimilação}

A Teoria da Equilibração das Estruturas Cognitivas [Piaget 1976] apresenta a aquisição de conhecimento como produto da equilibração entre dois processos cognitivos fundamentais que ocorrem nos indivíduos quando estão diante de algo novo: Assimilação e Acomodação. O processo de Assimilação é a absorção de um elemento exterior, seja um objeto, situação ou qualquer conteúdo novo, por um esquema conceitual ou sensório motor existente no sujeito. É o momento em que o indivíduo se esforça para encontrar dentro de si, um esquema, ou seja, um conhecimento que explique, que lhe proveja sentido e que seja familiar ao estímulo desconhecido, cuja inquietação emergiu pela falta de compreensão do mesmo. Por esse motivo, as regras do Hash 3D não podem ser transmitidas previamente aos jogadores, para que seja possível analisar os níveis de Planejamento, Atenção, Processamento Sucessivo e Simultâneo no momento da Assimilação, inferido na primeira partida do jogo.

\subsection{O Processo de Acomodação}

A Acomodação é o surgimento da necessidade de considerar as peculiaridades do novo elemento exterior assimilado, processo no qual se origina um novo esquema conceitual ou sensório motor, que modifica o conhecimento prévio existente. Sendo assim, o processo de Acomodação está sempre condicionado ao processo da Assimilação, porém, para que aconteça é necessária uma atividade, ou seja, um certo esforço do sujeito, caso contrário o ser humano poderia assimilar todo o universo sem se enriquecer em compreensão [Piaget 1976]. É no momento da Acomodação que a aquisição de conhecimento acontece e, por essa razão, que os processos de Planejamento, Atenção, Processamento Sucessivo e Simultâneo são analisados novamente na quinta e última partida do Hash $3 \mathrm{D}$, quando se presume que os jogadores já aprenderam as regras e o objetivo do jogo.

\subsection{A Psicomotricidade}

A Bateria Psicomotora (BPM) é um conjunto, de tarefas e situações, desenvolvido para analisar o perfil psicomotor das crianças [Fonseca 1995, 2012] em concordância com a organização funcional do cérebro proposta por Luria em 1966. Dentre os sete fatores psicomotores que a pesquisa de Fonseca aborda (Tonicidade, Equilibração, Lateralização, Noção do Corpo, Estruturação Espaço-Temporal, Praxia Global e Praxia Fina) o que mais contribuiu para este trabalho foi o estudo da Praxia Fina por tratar de funções como a coordenação dinâmica manual e a velocidade com precisão. Sendo assim, a velocidade e a precisão com que os jogadores manuseiam as peças, posicionando-as no tabuleiro sem deixálas cair e sem que esbarrem nas demais, indicam bons níveis de Praxia Fina por evidenciar a correlação entre a função exercida pelos músculos das mãos e o que está sendo observado, uma vez que essa íntima relação entre a visão e a velocidade com precisão, na coordenação 
dinâmica-manual, contribui para o desenvolvimento da aprendizagem, mais especificamente da leitura, da escrita e do cálculo matemático [Fonseca 2012].

\section{Trabalhos Correlatos}

No que diz respeito ao desenvolvimento de artefatos dotados de sensores e microcontroladores para manipulação física na interação com computadores, o Tangram Tangível, elaborado de forma colaborativa baseada no Design Centrado no Humano, uniu alunos e professores usuários como ferramenta de metodologia para projeção de artefatos tangíveis para aprendizagem. Utilizando recursos tecnológicos como Arduino Uno, Sensor Hall e Shield Bluetooth, o resultado foi a construção de sete peças físicas formadoras do Tangram Chinês, as quais se comunicam por meio de Bluetooth, com um aplicativo desenvolvido capaz de fornecer trilhas cognitivas que, posteriormente, podem ser utilizadas pelos professores para aferir a aprendizagem de cada aluno participante [Lima et al. 2016].

Em uma proposta diferente do uso de tecnologia para aferição de aprendizagem, mas em contribuição com aprimoramento da educação inclusiva, [Gluz et al. 2018] apresentaram um trabalho de integração sensorial no ensino de Ciências por meio de um ambiente virtual tangível. Os autores consideram que a ferramenta de ensino inovadora, capaz de integrar a tecnologia tangível com a realidade virtual, tem uma perspectiva inclusiva para os alunos com déficits na comunicação.

\section{Metodologia}

A elaboração de um Jogo Inteligente Tangível (JIT) se inicia conforme a metodologia desenvolvida para criação de um Game Inteligente [Marques 2015, 2017]. A primeira etapa, denominada Modelagem Dimensional, apresenta como o Game Inteligente se relaciona com a base teórica sobre a qual foi construído. A segunda etapa, denominada Processo Criativo, interliga os processos cognitivos, que se espera observar, à temática do jogo e sua ludicidade. Sendo assim, após a definição do Modelo Dimensional o jogo é inventado de forma que a arte e os episódios jogáveis sejam pareados com requisitos específicos, os quais são gerados após um estudo das suas possíveis interações e seus significados conforme as teorias científicas, originando regras estabelecidas para o jogador e para o engenho computacional que mapeia os resultados. Nesta etapa de criação que ocorre durante o Processo Criativo, a tangibilidade do artefato é primordial para a consolidação do jogo como um JIT, ou seja, peças físicas e totalmente manipuláveis precisam existir na interação com o computador. $\mathrm{Na}$ terceira etapa, denominada Projeto Interacional, profissionais de ensino estudam as respostas esperadas dos educandos e ponderam sua relevância no escopo do conhecimento que está sendo estudado [Marques 2017]. Dessa forma, são definidas as ações esperadas nas partidas do Hash 3D, conforme o embasamento teórico, como o bloqueio da vitória alheia ao impedir a formação sequencial do adversário, atitude que representa um ponto no processo de Atenção. Por fim, a última etapa, chamada Desenvolvimento Conceitual, detalha a mecânica e a dinâmica que compõem a arquitetura do jogo. Nessa etapa também são especificados os Crivos Computacionais ${ }^{4}$, os quais definem as ações e pontuações, assim como os dispositivos, linguagens de programação, algoritmos, softwares e ferramentas de inteligência artificial a serem utilizados.

\footnotetext{
${ }^{4}$ Os crivos são critérios neuropsicopedagógicos que definem as regras e as decisões existentes por trás das funções do design do jogo [Marques 2017].
} 
Após o desenvolvimento das etapas descritas, faz-se necessário acrescentar, no Modelo Dimensional, as análises de Praxia Fina e as possíveis ações que a definem no decorrer da partida, como a velocidade com precisão na manipulação das peças e a ausência de quedas e de esbarrões que configurem acidentes, para que o artefato seja consolidado como um Jogo Inteligente Tangível.

\section{A construção do Hash 3D}

A parte física do Hash 3D foi feita com MDF 3mm cortado em máquina $\mathrm{CNC}$ a laser. As pequenas caixas que constituem as peças tiveram seu mecanismo de encaixe desenhado com uma ferramenta disponível no site $<$ http://jeromeleary.com/laser/ $>$ para garantir a resistência das mesmas. Após o corte e montagem, todas as peças foram pintadas com tinta spray, conforme demonstrado na Figura 7.
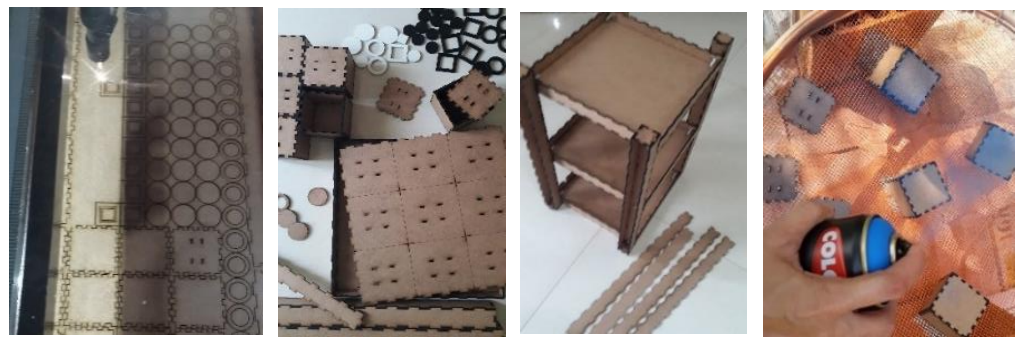

Figura 6. Processo da construção artística

O desenvolvimento do hardware e software iniciou-se após a realização do teste que verificou a funcionalidade do Hash $3 \mathrm{D}$, por meio de uma versão não computadorizada, utilizada com dez alunos voluntários do Ensino Fundamental. Na ocasião, os dados como o tempo de alocação das peças no tabuleiro, a identificação das peças, as casas de destino e a pontuação, conforme os crivos, foram coletados a partir da filmagem das partidas e preenchidos em uma planilha esquematizada para este fim [Scheffel 2019]. Mas para que a coleta de dados dos novos testes seja feita de forma computadorizada, conforme proposto nesta pesquisa, é necessário que o artefato permita que o computador faça a varredura de todas as casas do tabuleiro, de segundo em segundo, assim como reconheça quais peças foram posicionadas em quais casas, com o objetivo de promover a pontuação conforme especificado no Modelo Dimensional. Por esse motivo, as peças são nomeadas e numeradas, assim como as casas do tabuleiro, conforme demonstrado na Figura 1.

O hardware escolhido foi um Arduino Mega por possuir 16 portas analógicas capazes de receber sinais que variam entre os valores inteiros de 0 a 1023, condizente com a voltagem detectada. Porém, como o tabuleiro tridimensional possui 27 casas ( 9 por andar) foi necessário utilizar um multiplexador analógico/ digital de 16 canais Cd74hc4067 para expansão das portas analógicas existentes. Cabe dizer que na primeira tentativa de identificação das peças, as quais, inicialmente, teriam pesos diferenciados, foram utilizadas células de carga de até $1 \mathrm{~kg}$ e módulos de sensor de peso HX711 ADC 24 Bits em cada casa do tabuleiro, conectados às portas analógicas do Arduino ou do multiplexador. Além de onerar os custos com a confecção do protótipo e dificultar a programação, uma vez que as "balanças" deveriam ser calibradas em cada início de partida, a identificação das peças não se mostrou precisa, pois quando as mesmas eram posicionadas de forma descentralizada a variação, ocasionada pela má distribuição do peso, fazia com que o computador a identificasse como outra peça mais leve. Então, o que possibilitou o funcionamento do 
artefato com precisão, em todos os testes de montagem realizados, foi a utilização de divisores de tensão. Cada casa do tabuleiro possui dois contatos de cobre, um deles ligado na porta $5 \mathrm{~V}$ do Arduino, intermediado por um resistor de $5 \mathrm{k} \Omega$, e o outro ligado na porta GND. Cada peça do jogo possui resistores de valores diferenciados, ligados aos seus dois contatos de cobre, os quais possuem o mesmo afastamento dos contatos existentes no tabuleiro, permitindo que a corrente elétrica atravesse de um para o outro. Enquanto não há peças no tabuleiro, as casas enviam o sinal máximo de 1023 para as portas analógicas, cuja programação entende como ausência de peças. Quando uma das peças é alocada no tabuleiro, seu resistor diminui a tensão que o Arduino recebe naquela porta, alterando o sinal que não será mais de 1023, e a mesma será identificada conforme sua leitura prevista.

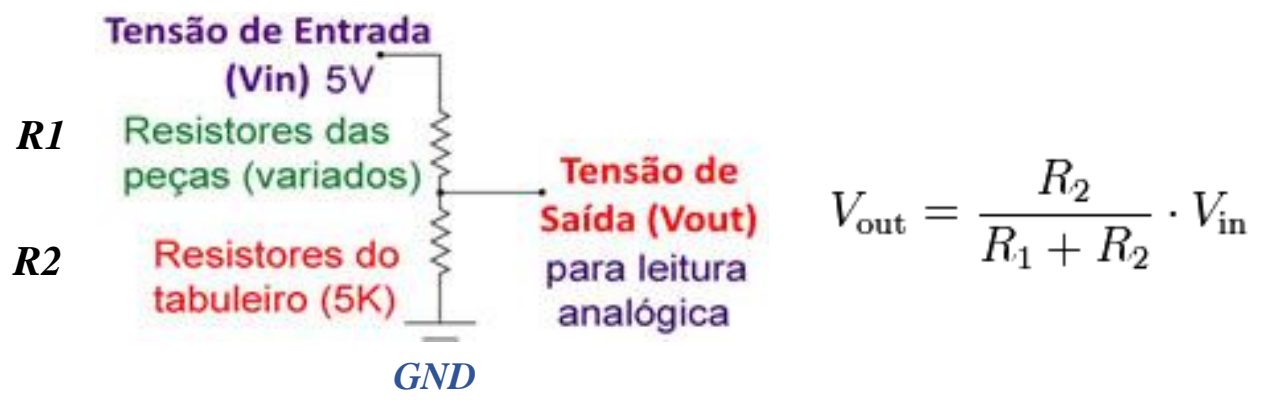

Quadro 2. Peças iniciais e seus resistores para leitura analógica

\begin{tabular}{|c|cc|c|c|c|c|}
\hline $\mathrm{N}^{\mathbf{0}}$ & Peças & $\begin{array}{c}\text { Leitura } \\
\text { Esperada }\end{array}$ & $\begin{array}{c}\text { Leitura Min. } \\
>=\end{array}$ & $\begin{array}{c}\text { Leitura Max. } \\
<\end{array}$ & $\begin{array}{c}\text { Resistência da } \\
\text { Peça }\end{array}$ \\
\hline 1 & $\bullet$ & AZ1 & 30 & 5 & 50 & $150 \Omega$ \\
\hline 2 & 0 & AZ2 & 66 & 50 & 83 & $345 \Omega$ \\
\hline 3 & & AZ3 & 103 & 83 & 116 & $560 \Omega$ \\
\hline 4 & 口 & AZ4 & 133 & 116 & 149 & $748 \Omega$ \\
\hline 5 & - & AZ5 & 166 & 149 & 182 & $970 \Omega$ \\
\hline
\end{tabular}

Aplicando a fórmula dos divisores de tensão (Equação 1) foi possível criar uma planilha contendo trinta diferentes valores de resistores, um para cada peça, além da leitura esperada pela porta analógica, de acordo com cada resistor, e uma margem de erro de leitura com variação mínima de $20 \%$, para mais ou para menos, conforme apresentado no Quadro 2. A consideração dessa variação na leitura é fundamental para que seja prevista na programação, a fim de impedir que o Arduino identifique peças erradas.

Após o funcionamento do sistema de identificação das peças e casas do tabuleiro, o segundo desafio foi garantir que as peças sejam sempre alocadas na posição correta, durante as partidas, uma vez que a falta de contato ocasionada por alguma peça que estivesse fora da posição poderia ocultá-la das análises e gerar erros nos resultados. Para isso, foram utilizados discos de ímã de neodímio com 10x4 mm de tamanho, peso de 2,4 g e 3700 Gauss de indução magnética, o equivalente a uma tração de $2,5 \mathrm{~kg}$ cada. Os ímãs não estão visíveis, eles foram posicionados na parte de dentro das peças e do tabuleiro, a fim de suavizar sua força magnética e prevenir dificuldades no manuseio. Cada casa do tabuleiro recebeu dois ímãs com os polos negativos para cima, dispostos de forma enviesada, e cada peça recebeu quatro ímãs, dois com os polos positivos e enviesados para baixo, atraindo a peça para a posição 
correta, e dois com os polos negativos para baixo, conforme apresentado na Figura 8, repelindo-as quando posicionadas erroneamente.

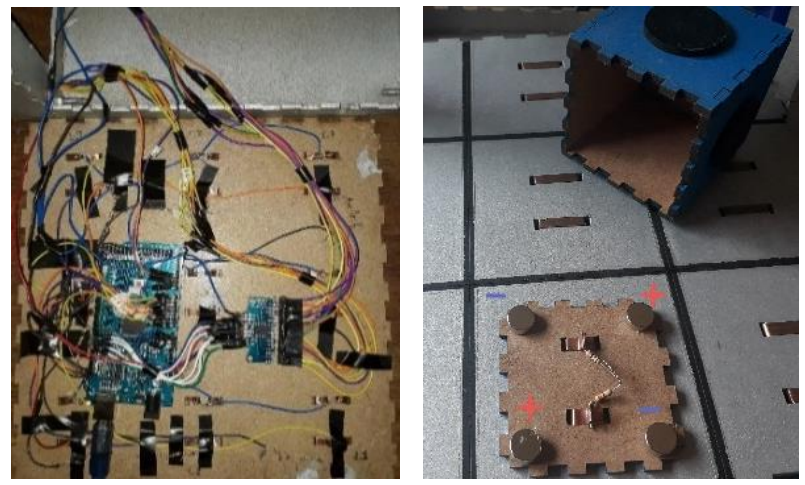

Figura 7. Interior do primeiro andar do tabuleiro e interior de peça AZ2

Com a efetiva leitura viabilizada pelo Arduino, a programação que proverá as análises em conformidade com as especificações dos Crivos Computacionais está sendo desenvolvida em Python, sob orientação do Programador Sênior Carlo E. T. Oliveira, do Instituto Tércio Pacitti de Aplicações e Pesquisas Computacionais da UFRJ. Para fazer a conexão entre o Arduino e a programação em Python foi utilizada a biblioteca Pyserial. Inicialmente foram elaborados algoritmos que reconhecem as sequências formadas com peças da mesma cor ou mesmo símbolo, pertencentes ao mesmo time (preto ou branco), nas retas horizontais, verticais e diagonais, classificando-as como acertos. O desafio atual é a elaboração de algoritmos que identifiquem os "meio acertos", ou seja, as situações que iniciam as formações sequenciais e que dão origem às ações caracterizadas como processos de Planejamento, Atenção, Processamento Sucessivo e Simultâneo.

\section{Considerações Finais e Trabalhos Futuros}

O presente trabalho apresenta o processo de construção de uma nova abordagem para mensuração de aspectos cognitivos por meio de um artefato lúdico, dotado da tangibilidade, cujo design remete aos brinquedos tradicionais, ao mesmo tempo que dispõe de tecnologia e inovação.

O Hash 3D encontra-se em fase avançada de desenvolvimento, onde o artefato físico, incluindo o acabamento artístico e a montagem do circuito eletrônico, está finalizado e funcionando com sucesso na detecção das peças, por meio da interface com o Arduino. A atual programação em Python é capaz de consolidar os acertos provocados pelas jogadas nas quais são finalizadas sequências de três peças da mesma cor ou de mesmo símbolo, o que significa que foi concretizado o primeiro passo para as futuras análises computadorizadas das ações que ocorrem durante as partidas do jogo.

Como trabalho futuro, espera-se que os algoritmos de análise sejam finalizados e que o Hash 3D seja testado com novos alunos voluntários. Além disso, com o intuito de comparar resultados e validar a abordagem proposta nesta pesquisa, a intenção é aplicar o teste CAS (Cognitive Assessment System), proposto por Das e Naglieri (1994, 2001), nos mesmos alunos participantes do experimento com o Jogo Inteligente Tangível, uma vez que ambos 
visam mensurar os níveis de Planejamento, Atenção, Processamento Sucessivo e Processamento Simultâneo.

\section{Referências}

Fonseca, V. (1995) "Manual de observação psicomotora: significação psiconeurológica dos fatores psicomotores". 1.ed. Artes Médicas, Porto Alegre.

Das, J. P., Naglieri, J. e Kirby, J. (1994) "Assessment of Cognitive Processes: The PASS Theory of Intelligence". $1^{\text {a }}$. ed. Allyn and Bycon, Boston.

Gluz, J., Passerino, L., Preuss, E., Baierle, I. e Cimadevila, M. (2018) "Ambiente Virtual Tangível para Integração Sensorial no Ensino de Ciências numa Perspectiva Inclusiva”. In Anais do SBIE 2018, p. 545-554.

Inhelder, B., Cellérier, G., Ackermann, E., Blanchet, A., Caprona, D., Ducret, J. e Robert, M. (1996) "O Desenrolar das descobertas da criança: pesquisa acerca das microgêneses cognitivas". Trad. Eunice Gruman. Artes Médicas, Porto Alegre.

Lima, I., Castro, T., Dantas, A. e Siqueira, M. (2016) "Processo de Design Colaborativo de Artefatos Tangíveis para Crianças”. In Anais do XXXVI CSBC, p. 1408-1422.

Luria, A. (1966) "Human Brain and Psychological Processes". 1 a . ed. Harper \& Row, Nova York.

Luria, A. (1973) "The Working Brain: An introduction to neuropsychology". 1 a. ed. Basic Books, Nova York.

Luria, A. (1980). "Higher Cortical Functions in Man”. $2^{\text {a }}$ ed. Springer, Nova York.

Marques, C. (2017) "EICA - Estruturas Internas Cognitivas Aprendentes: Um Modelo Neuro-Computacional aplicado à instância psíquica do Sistema Pessoa em Espaços Dimensionais". Tese de Doutorado. COPPE/ UFRJ, Rio de Janeiro.

Marques, C., Calil, E. e Brasil, G. (2015) "Game Inteligente: conceito e aplicação". In Anais do Seminário de Jogos Eletrônicos, Educação e Comunicação, v. 1, n. 1, p. 162-171.

Naglieri J. (2001) Cognitive Assessment System (CAS). In Dorfman W.I., Hersen M. (eds) Understanding Psychological Assessment. Perspectives on Individual Differences. Springer, Boston, p. 235-257.

Piaget, J. (1976) "A Equilibração das Estruturas Cognitivas: Problema Central do Desenvolvimento". Zahar Editores, Rio de Janeiro.

Piaget, J. (1986) “O nascimento da Inteligência da Criança”. 10. ed. Dom Quixote, Lisboa.

Scheffel, E., Motta C. e Marques, C. (2019) “Jogos Inteligentes Tangíveis como Instrumento de Mensuração Cognitiva” In Anais do SBIE 2019, p. 1042-1051.

Zuckerman, O., Arida, S. e Resnick, M. (2005) "Extending Tangible Interfaces for Education: Digital Montessori-Inspired Manipulatives” In Proceeding of CHI 05. 